\title{
Evaluation of accuracy of seamless steel tube scanning by industrial computed tomography
}

\author{
Michaela Kritikos ${ }^{1,}$, Ivan Buranský $^{1,}{ }^{*}$, Eva Buranská $^{2}$ and Milan Mojžiš ${ }^{3}$ \\ ${ }^{1}$ Slovak University of Technology, Faculty of Materials Science and Technology in Trnava, Institute \\ of Production Technologies, J. Bottu 24, Trnava, Slovakia \\ ${ }^{2}$ Slovak University of Technology, Faculty of Materials Science and Technology in Trnava, Institute \\ of Integrated Safety, J. Bottu 24, Trnava, Slovakia \\ ${ }^{3}$ ŽP Výskumno-vývojové centrum s.r.o. (ŽP VVC s.r.o.), Kolkáreň 35, Podbrezová, Slovakia
}

\begin{abstract}
Measurement by computed tomography is very useful in evaluation of dimensions and internal structure. There are still some problems which need to be solved. Scanning accuracy depends, among other things, on the part's material. Metal parts have high density and their scanning leads many times to failure. This paper deals with evaluation of accuracy of seamless steel tube scanning by industrial computed tomography. This method of scanning can lead to substitution of destructive method for measurement, but it is necessary to have knowledge if the scan has required accuracy. The tube with different diameters in length is scanned by X-Ray beam and it is evaluated inner and outer diameter, concentricity and wall thickness in 8 sections. The accuracy of scan is compared with reference values achieved by coordinate measuring machine in the same sections.
\end{abstract}

\section{Introduction}

$\mathrm{X}$-ray $\mathrm{CT}$ is a three-dimensional measurement technique with many advantages for industrial inspection and quality control. It enables the inspection of parts' internal and external features in a non-destructive fashion, and the creation of a 3D model for the entire volume of a scanned object. It has the ability to generate geometric data for the characterization of material structures and detection of manufacturing imperfections and faults. Major manufacturing companies in the automotive, aerospace and aviation, medical and biomedical, electronic, and other engineering industries are interested in using CT for the inspection of a variety of applications with plastics, polymers, ceramics, casting and light metals (e.g. aluminium), additive manufacturing, fibres, composite materials, and

\footnotetext{
*Corresponding author: ivan.buransky@stuba.sk
} 
assemblies[1]. The technique is widely used for quality control, but it is not as well known for its capacity to evaluate dimensional information [2]. At the present time, some modern industrial X-ray CT machines can provide parts' dimensional results with "measurement uncertainties" as small as $4 \mu \mathrm{m}$ when special calibrations are applied. This means that small measurement deviations compared to coordinate measurement machines (CMM)can be obtained, and in some cases, achieving deviations as low as $1 \mu \mathrm{m}$ or less [3]. The conventional CMM techniques cannot be used effectively in some situations, such as when the object has internal geometry or difficult-to-reach part features or if its components are made of soft or flexible structures. References $[4,5,6]$ illustrates the challenges of CMM and the potential of X-ray CT for reliable dimensional inspection [9].

\section{Seamless steel tube characterisations}

The technological process of manufacturing cold-drawn seamless tubes (Figure 1) consists of the following operations - swaging, chemical preparation of the surface of the pipes, cold drawing, heat treatment (polygonation) and final heat treatment in a protective atmosphere in continuous annealing furnaces, finishing, surface inspection, packaging, preservation and expedition [7].

The dimensional and shape stability of the required dimensions of the steel pipes has a major impact on the further treatment of the process of the tubes (second production).

Tolerances of the precision tubes are in accordance with the appropriate dimensional tables of standards. Usual value for the tolerance of outer diameter (OD) is less than $0.5 \%$ of OD in no heat treatment process used. For the heat-treated tubes, tolerance values are depended upon the relation of the wall thickness and the tube diameter (WT/OD) and are larger (up to a single or twofold). In tolerances of the outer diameter (OD) the allowed deviation of circularity is included. Concentricity of precision tube is included in the wall thickness tolerance [8].

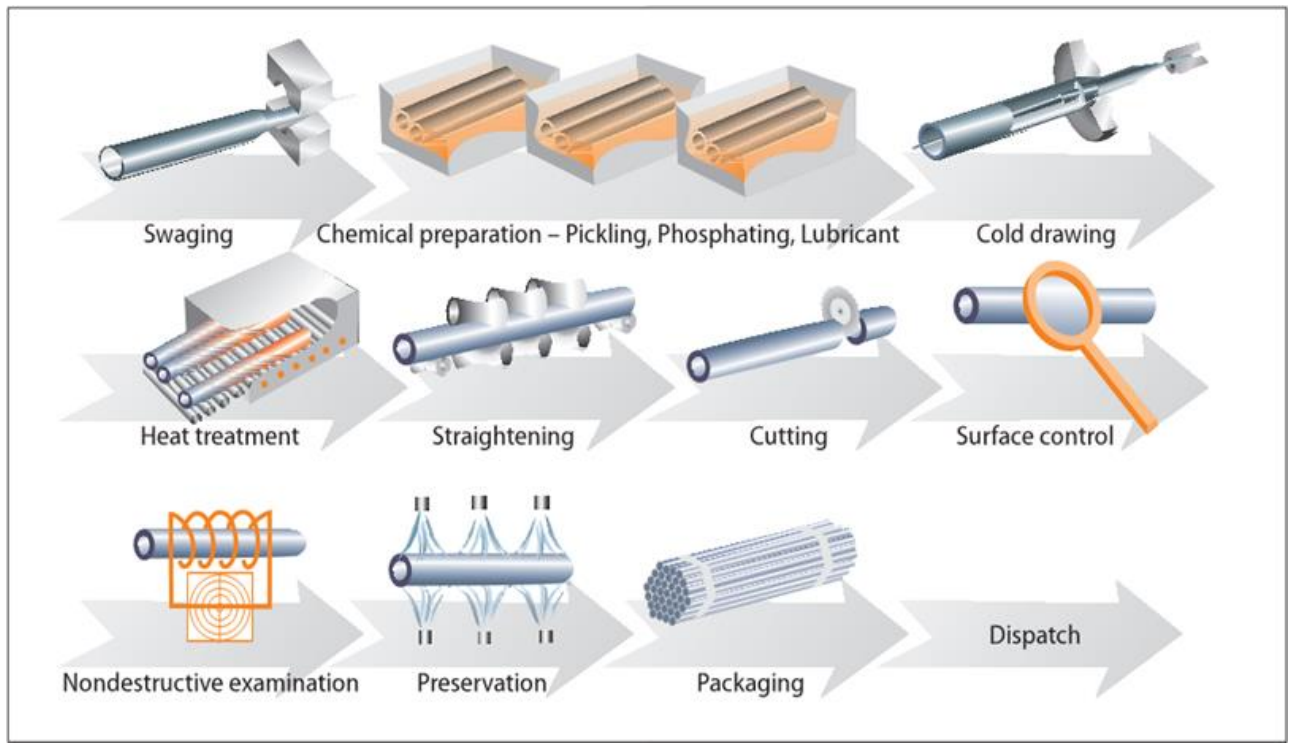

Fig. 1. Diagram of production flow of cold-drawn steel tubes [7,8] 


\section{Experimental investigations}

Steel tube samples for the measurement were prepared from one type of cold drawn tube with a wall thickness of $4 \mathrm{~mm}$, which was turned into individual wall thicknesses from 0.5 $\mathrm{mm}$ to $4 \mathrm{~mm}$. Figure 2 shows tube made of steel (STN 11.353.1) with different wall thicknesses.

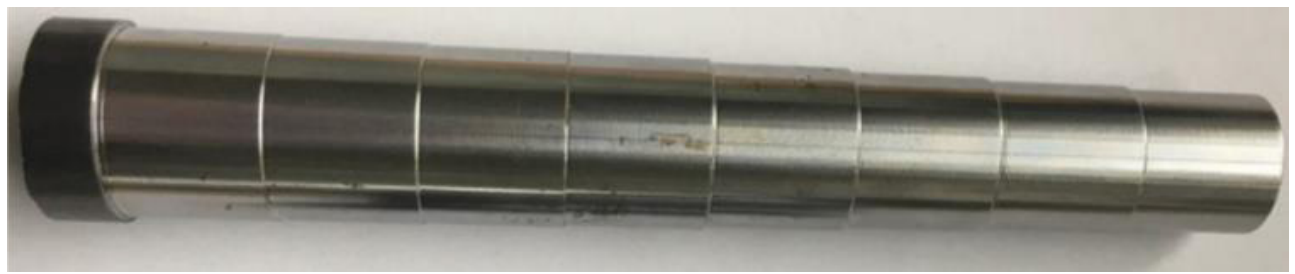

Fig. 2. Steel tube turned to different wall thicknesses

Turned steel tube with 8 different diameters in length was measured by coordinate measuring machine CenterMAX from Zeiss company. This machine is situated in Centre of Excellence of 5 - axis machining at Slovak Technical University in Bratislava, Faculty of Materials Science and Technology in Trnava. It is robust machine with pneumatic vibration insulation and temperature stability from $+15^{\circ} \mathrm{C}$ to $+40^{\circ} \mathrm{C}$. The ZEISS VAST XTR gold head was used for measurement. Length measurement error is different for different temperatures. In our conditions $\left(26^{\circ} \mathrm{C}\right)$ it is $1.5+\mathrm{L} / 250(\mu \mathrm{m})$.

Calypso software was used for programming of measurement (Fig. 3). The alignment was created by the upper plane and the inner cylinder in whole length. Stylus system with diameter of $8 \mathrm{~mm}$ was calibrated before the measurement. Inner and outer circles in different sections were measured $-10 \mathrm{~mm}, 30 \mathrm{~mm}, 50 \mathrm{~mm}, 70 \mathrm{~mm}, 90 \mathrm{~mm}, 110 \mathrm{~mm}, 130 \mathrm{~mm}$, $150 \mathrm{~mm}$ from the upper plane.

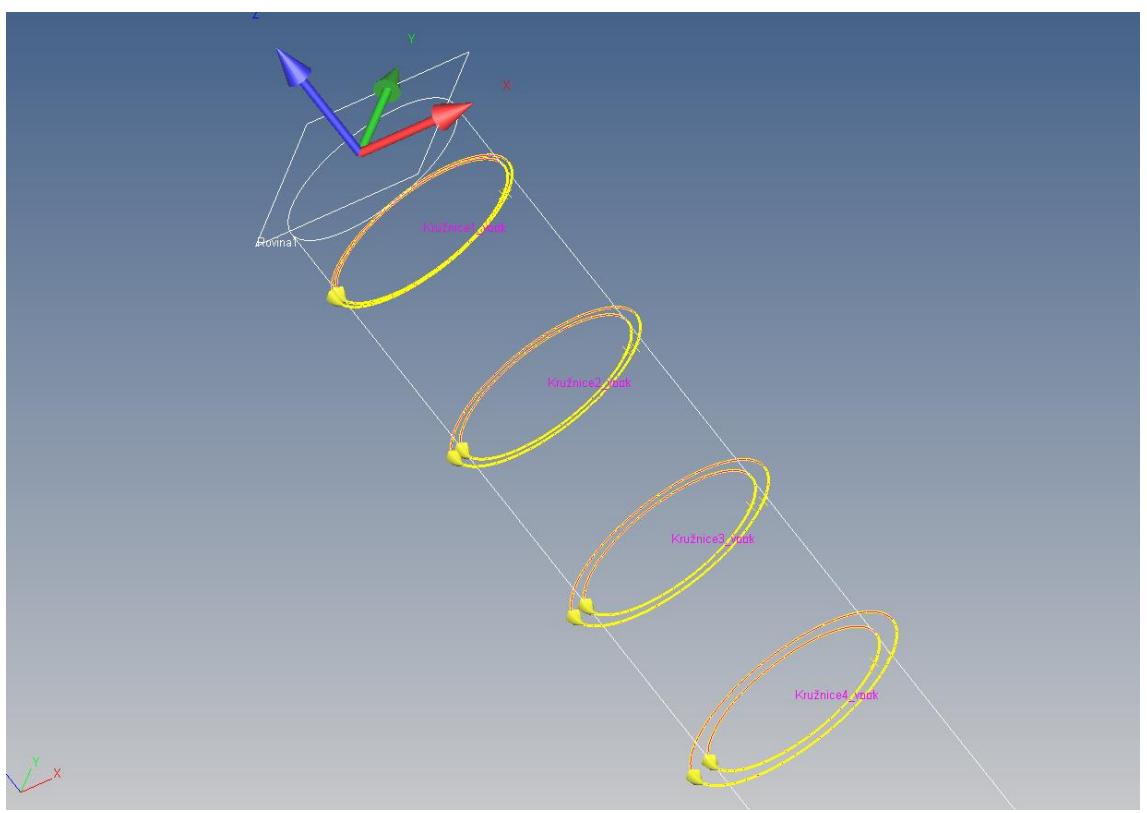

Fig. 3. Calypso software programming 
Data from this measurement were used as reference values for comparison with data gotten from CT device - METROTOM 1500 from Zeiss company. It is an industrial computed tomography system for measuring and inspecting complete components made of plastic or light metal. Specification of the equipment is in the Table 1.

Table 1. METROTOM 1500 specification.

\begin{tabular}{|c|c|}
\hline Tube power & $500 \mathrm{~W}$ \\
\hline Tube voltage & $225 \mathrm{kV}$ \\
\hline Current & $1000 \mu \mathrm{A}$ \\
\hline Measuring range & dia. $350 \mathrm{~mm} \times 300 \mathrm{~mm}$ \\
\hline Detector resolution & $1024 \times 1024 \mathrm{px}$, \\
$2048 \times 2048 \mathrm{px}$
\end{tabular}

This experimental investigation was examined at a distance of $650 \mathrm{~mm}$ from X- Ray lamp with voxel size of $172 \mu \mathrm{m}$. Software used for scanning was METROTOM OS 2.8 (Fig. 4). Integration time was $1000 \mathrm{~ms}$ per picture and it was used 1050 pictures for evaluation. It took 40 minutes of scanning. Voltage value was $190 \mathrm{kV}$ and current was used $800 \mu \mathrm{A}$.

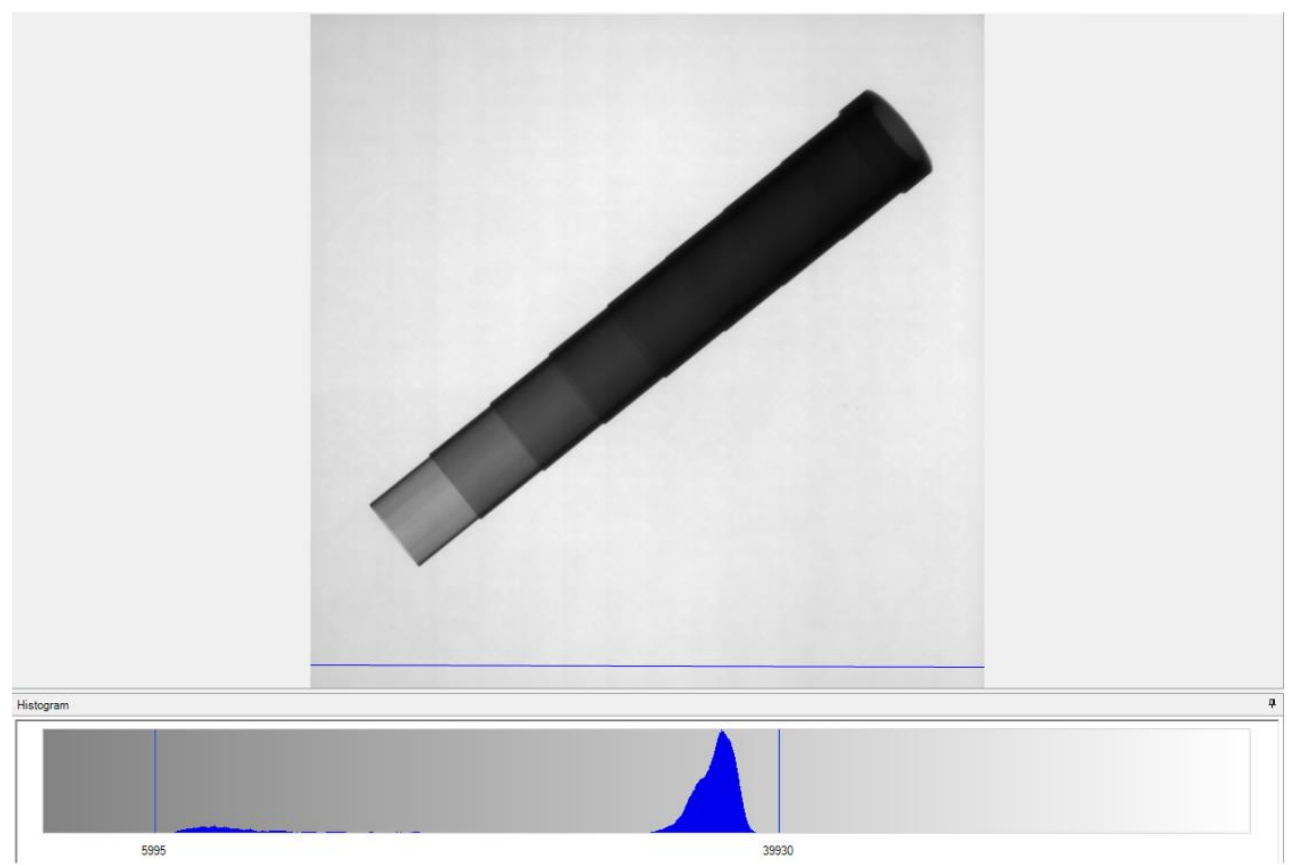

Fig. 4. METROTOM OS 2.8 software 
Tube's 3D scan is illustrated in the Fig. 5a) and the sections of evaluations are in the Fig. 5b). As it is seen scanning was successful according to surface visibility. The accuracy of the dimensions was evaluated by these representatives: diameters, wall thickness, concentricity.

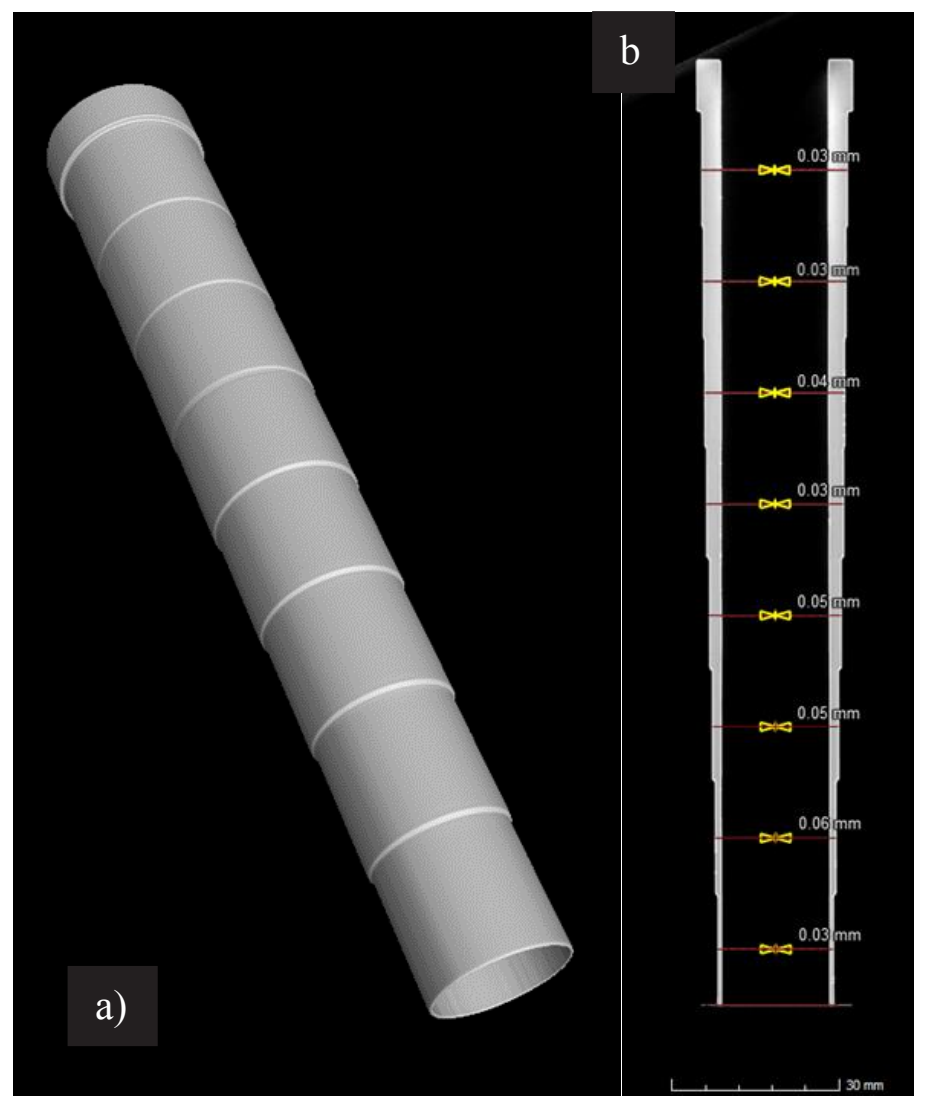

Fig. 5. a) 3D Scan of the tube, b) Sections of evaluation

\section{Results}

In the table 2 are reference values from CenterMAX in comparison to evaluated values from CT for wall thickness evaluation. Wall thickness differences are in the range of -0.043 $\mathrm{mm}$ and $-0.084 \mathrm{~mm}$. The highest difference was achieved in the section of $70 \mathrm{~mm}$ from upper plane and the lowest difference was achieved in the section of $130 \mathrm{~mm}$. 
Table 2. Results of steel tube's wall thickness.

\begin{tabular}{|c|c|c|c|}
\hline Distance $(\mathrm{mm})$ & $\begin{array}{c}\text { Reference wall thickness } \\
(\mathrm{mm})\end{array}$ & $\begin{array}{c}\text { Wall thickness CT } \\
(\mathrm{mm})\end{array}$ & $\begin{array}{c}\text { Difference } \\
(\mathrm{mm})\end{array}$ \\
\hline 10 & 0.503 & 0.550 & -0.047 \\
\hline 30 & 0.994 & 0.935 & -0.059 \\
\hline 50 & 1.513 & 1.445 & -0.068 \\
\hline 70 & 2.049 & 1.965 & -0.084 \\
\hline 90 & 2.541 & 2.495 & -0.046 \\
\hline 110 & 2.831 & 2.780 & -0.051 \\
\hline 130 & 3.068 & 3.025 & -0.043 \\
\hline 150 & 3.326 & 3.280 & -0.046 \\
\hline
\end{tabular}

Evaluation of concentricity deviations is illustrated in the Table 3.

Table 3. Results of steel tube's concentricity deviations.

\begin{tabular}{|c|c|c|c|}
\hline Distance $(\mathrm{mm})$ & $\begin{array}{c}\text { Reference concentricity } \\
(\mathrm{mm})\end{array}$ & $\begin{array}{c}\text { Concentricity CT } \\
(\mathrm{mm})\end{array}$ & $\begin{array}{c}\text { Deviation } \\
(\mathrm{mm})\end{array}$ \\
\hline 10 & 0.065 & 0.030 & -0.035 \\
\hline 30 & 0.075 & 0.060 & -0.015 \\
\hline 50 & 0.032 & 0.050 & 0.018 \\
\hline 70 & 0.016 & 0.050 & -0.034 \\
\hline 90 & 0.039 & 0.030 & 0.006 \\
\hline 110 & 0.035 & 0.040 & 0.002 \\
\hline 130 & 0.028 & 0.030 & 0.008 \\
\hline 150 & 0.022 & 0.030 & \\
\hline
\end{tabular}


The concentricity differences are in the range of $-0.035 \mathrm{~mm}$ and $0.034 \mathrm{~mm}$. Half of differences are lower than $0.01 \mathrm{~mm}$. The closest value of concentricity to reference value was achieved in the section of $130 \mathrm{~mm}(0.002 \mathrm{~mm})$.

\section{Conclusions}

The shape stability of the steel tubes has a major influence on the further technological process of the tube processing, i. e. on secondary production. It is a very important parameter in terms of functionality, for example, active and passive parts of a car, where the dimensional tolerance fields are one of the toughest in terms of production itself.

The paper deals with evaluation of accuracy of seamless steel tube scanning by industrial computed tomography. If the accuracy of scan achieved from computed tomography is suitable for scanning and evaluation of seamless steel tubes it will lead to more flexible control because of application of non - destructive method.

This experimental investigation leads to conclusion that CT scanning of the seamless steel tube is satisfying. Achieved CT data (inner, outer diameter, wall thickness and concentricity) are in the tolerance (required limit is less than $0,5 \%$ from outer diameter).

Results leads also to possibility of CT application in the measurement and evaluation of the seamless steels with inner profile dimensions which are controlled by destructive method. Their the highest wall thickness is $4 \mathrm{~mm}$.

Differences can be effected by surface recognition in the software for CT data evaluation and by scanning conditions (voltage, current, voxel size, integration time, number of pictures). It could be also interesting to achieve CT data by different scanning conditions and to compare results.

The article was written with the support of the APVV project of Slovak Research and development Agency of the Ministry of Education, Science, Research and Sport of the Slovak Republic, no. APVV-18-0418 : "Research on causes of geometrical deviations in the production of seamless tubes and their technological inheritance with emphasis on the shape stability of precision cold drawn tubes using metrological systems."

\section{References}

1. L. De Chiffre, S. Carmignato, J. P. Kruth, R. Schmitt, A. Weckenmann, CIRP ANNMANUF TECHN, 63, 655-677, (2014)

2. H. Villarraga-Gómez, Quality Magazine, 55, 20-23, (2016)

3. F. Léonard, S. B. Brown, P. J. Withers, P. M. Mummery, M. B. McCarthy, Meas. Sci. Technol., 25, 1-10, (2014)

4. H. Villarraga-Gómez,E. P. Morse, R. J. Hocken, S. T. Smith, 29th ASPE Annual meeting, Boston, 684-689, (2014)

5. H. Villarraga-Gómez, D. O. Clark, S. T. Smith, ASPE Mets \& Props J. Phys. Conf. Ser., 60, 1-7, (2015)

6. H. Villarraga-Gómez, C. Lee, S. P. Charney, J. A. Tarbutton, S. T. Smith, ASPE Spring Topical Meeting, Raleigh, 164-169, (2015) 
7. M. Ridzoň, 1st ed. - Köthen: Hochschule Anhalt, Scientific monographs, (2012)

8. M. Ridzoň, M. Mojžiš, P. Bella, L. Parilák, M. Kán, I. Buranský, Metalurgija, 58, 3-4, (2019)

9. X-ray Computed Tomography for Dimensional Measurements, www.researchgate.net/publication/305692057_X-

ray_Computed_Tomography_for_Dimensional_Measurements 